\title{
EI museo, constructor de otros contextos. Cien años del Museo Nacional de Artes Decorativas
}

\author{
Sofía RodRÍGUEz BERNIS \\ Directora del Museo Nacional de Artes Decorativas \\ sofia.rodriguez@mecd.es \\ Paloma Muñoz-CAMPOS GARCÍA \\ Conservadora del Museo Nacional de Artes Decorativas \\ paloma.munozcampos@mecd.es
}

\begin{abstract}
Resumen
El Museo Nacional de Artes Decorativas es fruto del trabajo de muchos profesionales cuya experiencia ha permitido que la institución evolucione y se transforme a tenor de los tiempos. El actual equipo de trabajo ha querido aportar nuevos objetivos e iniciativas para exponer las colecciones, creando contextos no solo estilísticos, sino también comerciales y productivos, de uso, ideológicos y simbólicos. Pero antes de llegar este punto, el museo, que cuenta con cien años de historia, ha pasado por distintos proyectos acordes a las circunstancias sociales y políticas de cada época.
\end{abstract}

Palabras clave: Museo de Artes Industriales, Museo de Artes Decorativas, museografía, colecciones, artes industriales, artes decorativas, diseño, cultura material.

\section{The Museum, a Constructor of Other Contexts. One Hundred Years of the Museo Nacional de Artes Decorativas}

\begin{abstract}
The Museo Nacional de Artes Decorativas is the result of the work of many professionals whose experience has enabled the institution to evolve and transform according to the times. The current working team wanted to provide new targets and initiatives to exhibit the museum collections creating contexts based not only on stylistic criteria, but also on commercial, productive, utilitarian, ideological and symbolical issues. But before reaching this point, the Museum, which has one hundred years of history, has gone through various projects appropriate to the times and to social and political circumstances.
\end{abstract}

Key words: Museo de Artes Industriales, Museo de Artes Decorativas, Museography, Collections, Industrial Arts, Decorative Arts, Desing, Material Culture. 
El museo conocido actualmente con la denominación de Nacional de Artes Decorativas, lo fue antaño con la de Nacional de Artes Industriales y lo será, esperamos, en un plazo razonable de tiempo, con otra más acorde con su actual filosofía ${ }^{1}$. Desde el inicio de su historia ha tenido que elegir, por las especiales características de la tipología en la que se incluye, relacionada con la producción de objetos de consumo y con la vida cotidiana, el sentido que la presentación de sus piezas debía de tener para el público visitante. La opción formalista, el mero mostrar objetos más o menos bellos o más o menos costosos, aunque a veces ha sido una tentación, se ha visto superada siempre en el museo gracias a los compromisos que ha ido adquiriendo con su época - o con sus distintas épocas-. Nunca ha dado la espalda a la realidad, aunque su relación con esta haya sido de variado signo, e incluso contradictoria.

Examinaremos cómo se ha materializado ese proceso en sus distintas etapas.

\section{2-1932. EI Museo Nacional de Artes Industriales}

El s. XX se iniciaba en España con un problema no resuelto: la potenciación de las débiles industrias que fabricaban productos para el consumo. Aquí, la mecanización, la organización del trabajo, la formación de los trabajadores y la definición de nuevos criterios estéticos, es decir, los fundamentos de la segunda Revolución Industrial, evolucionaban a la zaga de la Europa industrializada. En los años ochenta del XIX, la iniciativa de los sectores económicos e intelectuales más activos, apoyada en una política arancelaria proteccionista, había logrado acicatear el rendimiento y la calidad del sector de las, por entonces, llamadas "artes industriales". Treinta años después, cuando se creó el museo, estas mejoras aún no resultaban suficientes para que nuestro país fuera competitivo. El anuario del MNAI de 1916 -el único publicado- se hacía eco de esta preocupación y la relacionaba con la razón de su existencia:

"El personal de este museo... hizo un cálculo de lo que aproximadamente importaba España al año en objetos de artes industriales, pasando la cifra obtenida de cincuenta millones de pesetas... Una de las finalidades (del museo), ha de ser la más amplia difusión de sus elementos de cultura en las industrias artísticas... disminuyendo la cifra... (que) paga nuestra nación a las extranjeras al comprarles objetos que nosotros no producimos o elaboramos mal"'2.

\footnotetext{
1 La historia del MNAD ha sido objeto de varios estudios recientes, a los que este artículo debe mucho de su contenido: A. CABRERA LAFUENTE y M. VILLALBA SALVADOR, "El Museo Nacional de Artes Decorativas (Madrid): de Museo Industrial a Museo Nacional de Artes Industriales (1850-1912). Antecedentes para la Historia del Museo", Revista de Museología, 30-31 (2004), pp. 81-88, y 36 (2006), pp. 117-123; A. CABRERA LAFUENTE y M. VILLALBA SALVADOR, "El MNAD hace historia (I). Hace casi 100 años... el Museo Nacional de Artes Industriales", Estrado. Boletín del Museo Nacional de Artes Decorativas, 3 (2008), p. 27; F. SÁEZ LARA, "El MNAD hace historia (II y III). De los orígenes a la perspectiva actual: evolución conceptual", Estrado. Boletín del Museo Nacional de Artes Decorativas, 4 (2009), p. 56, y 5 (2009), p. 41.

2 Museo Nacional de Artes Industriales. Anuario de MCMXVI, p. 3.
} 


\section{Contexto y objetivos}

En el mundo de las exposiciones internacionales y universales, nuestro país solo había destacado por las producciones decorativas y artesanales, fabricadas en series limitadas. Eusebio Zuloaga, que había recibido una primera medalla en la de 1862, es quizá el representante más conspicuo de ese moderado éxito español: la modesta metalurgia vasca se convirtió, en sus manos, en obra de arte, gracias a los prolijos damasquinados que adornaban sus objetos ornamentales, de tipologías tradicionales. Ese embellecimiento de la modernidad con el vestido de la tradición es lo que permitió a España hacerse un cierto hueco en la Europa de su tiempo ${ }^{3}$.

Consciente de ese potencial, el Ministerio de Instrucción pública creó el MNAI para "fomentar el trabajo artístico" aplicado al sistema industrial. El decreto de fundación, de 30 de diciembre de 1912, explicaba este propósito, que matizaba así: "tendrá como función esencial, no la mera delectación artística y contemplativa, sino el promover la cultura artística y técnica de la artes aplicadas en el público, y especialmente en los artistas, industriales y obreros" ${ }^{4}$. Su vocación se planteaba como principalmente pedagógica y formativa, siguiendo el modelo establecido sesenta años antes por el South Kensington Museum -hoy V\&A-. Hay que decir que la intención de constituir un museo de esta tipología existía desde antiguo, ya que hubo un par de iniciativas fallidas en 1851 y 1871.

Las incipientes colecciones ofrecieron al "artista industrial" un modelo matizado por el "buen gusto", más próximo al mundo de las artes que a la estética de la máquina que pugnaba por abrirse camino en otros foros europeos y americanos. Es reflejo de este posicionamiento, por ejemplo, que una de las adquisiciones de fondos contemporáneos, destacadas por el mencionado anuario, fuera un conjunto de muestras de los papeles pintados y las telas de Morris \& $\mathrm{C}^{\mathrm{o}}$, diseñados hacía más de veinte años. Esta inclinación, sin embargo, solo era retardataria en apariencia; si Morris gustaba, era porque propugnaba la recuperación de antiguas técnicas e inspiraciones esenciales, rescatadas de una experiencia gremial en la que el trabajo era espiritualmente enriquecedor y no alienante.

Un espíritu parecido está en el origen de la contribución más innovadora del museo: la recuperación de la cultura popular tradicional, valorada por el Regeneracionismo, la generación del 98 y la Institución Libre de Enseñanza -y sus derivados- por su simplicidad fundamental, no contaminada por los historicismos decimonónicos con ínfulas aristocráticas, y por la sencillez y enraizamiento local de los procedimientos de fabricación. Se apreciaba doblemente por ser manifestación del amor al trabajo y de las capacidades manuales que fomentaba la pedagogía más avanzada. Los responsables de la etapa inicial de museo compartían estos presupuestos. Rafael Domènech, el primer director del MNAI, había publicado el catálogo de la Exposición de Artes Decorativas, celebrada en Madrid un año antes de la fundación del museo,

3 Lo mismo sucedió con el resto de los fabricantes que recibieron premios en los certámenes celebrados más allá de los Pirineos, como la firma Malvehy de sederos barceloneses especializados en brocados y brocateles, la platería Meneses y tantos otros.

4 Decreto fundacional, 30 de diciembre de 1912. 
con motivo de la cual Manuel Cossío redactó el artículo "Elogio del arte popular". Domènech, Pérez Bueno y Francisco Pérez Dolz - catedrático de la Escuela de Artes y Oficios y agregado del Museo- visitaron, pensionados por la Junta para la ampliación de estudios, el museo de Bethnal Green, dependiente del V\&A, dedicado a las artes populares ${ }^{6}$.

\section{Las colecciones: organización y exposición}

Muchas de las piezas fundacionales proceden, precisamente, de la producción "popular", tal y como se interpretaba a principios del s. XX: camisas bordadas salmantinas, sillas de palos, arcas de diferentes áreas geográficas en las que la decoración encarnaba la identidad local, cerámicas de los diferentes alfares españoles... Todas ellas se expusieron en el piso segundo del número 5 de la calle Sacramento junto a objetos más "cultos": limosneros de Dinand, colchas indoportuguesas, antiguas sedas labradas... Esa mixtura de "objetos antiguos y modernos", como decía el real decreto de creación del museo, tenía un claro propósito: enseñar "procedimientos, técnicas, materiales y decoraciones" a los trabajadores de las industrias artísticas. Todos los niveles de la producción humana, con independencia de que la erudición los hubiera calificado de "mayores" o "menores" se yuxtapusieron en las salas, sin que ninguno tuviera prioridad sobre el resto. Con fines también educativos, este método ya había sido utilizado por otros reformistas: Juan Facundo Riaño había hecho convivir en las páginas de su libro Spanish Arts al Disco de Teodosio de la Real Academia de la Historia con los encajes de Almagro, como manifestaciones igualmente representativas de la cultura hispana; y Cossío había acopiado para el Museo Pedagógico un extraordinario conjunto de bordado tradicional junto con reproducciones de las obras maestras de la pintura.

Un puñado de fotografías de la etapa fundacional muestra la ordenación de las colecciones en las salas de exposición: las distintas producciones se muestran en series, combinadas entre sí para evitar "toda la aridez posible de cosa muerta", y cada objeto se pone "en una disposición igual o parecida a la que tuvo"7. Una incipiente evocación de la función, que trataba de sugerir visualmente lo mismo que el principio enunciado por Louis Sullivan, que inspiraría al diseño racionalista del s. XX: la forma sigue a la función.

5 J.M. SÁNCHEZ RON (coord.), 1907-1987, la Junta para Ampliación de Estudios e Investigaciones Científicas 80 años después, II, Madrid, 1988, p. 580.

6 Esta concepción tuvo una larga vida, y estuvo, de cerca o de lejos, ligada a los intentos de renovación, racionalización y simplificación de las artes industriales. El Noucentisme catalán también se inspiró en la calidad de los objetos de uso común de la tradición; y todavía en 1923 la Exposición Internacional del mueble y la decoración de interiores celebrada en Barcelona (Montjuïc) convocaba un concurso "para la belleza del hogar humilde".

7 Anuario, op. cit., p. 9. 


\section{Productos culturales y público destinatario}

El MNAI contó con una sección dedicada a la "pedagogía de las artes industriales". Aunque las actividades organizadas están aún poco estudiadas, se sabe que se prepararon "series técnicas" que sirvieran de ejemplo a los artesanos e industriales: esmaltes translúcidos, bordados, batiks, tarso (decoración polícroma de la madera para ebanistería), unidades decorativas talladas en madera, y alguna más; en parte se han conservado. Asimismo, por lo menos dos de las telas de Morris y un tejido antiguo se montaron sobre cartones, con dibujos adyacentes en los que se apuntaban las líneas compositivas; solo una de estas composiciones ha llegado hasta nuestros días. Además, el personal del museo atendía a las consultas de "artistas decoradores e industriales", y corregía los proyectos que se le sometían.

Los visitantes, unos cuarenta anuales, firmaban un libro, gracias al cual sabemos que también arquitectos, artistas e investigadores frecuentaban el museo; en él aparecen, entre otras, las rúbricas de Gutiérrez Soto, José María Muguruza, Luis Martínez Feduchi, Sáenz de Tejada, Gregorio Prieto, Benjamín Palencia, Luis Quintanilla, Carmen Baroja y García Bellido.

\section{7- 1973. El Museo Nacional de Artes (más que nada) Decorativas}

En 1927 el museo abandonó el camino hacia la industria moderna, del que las tentaciones de artisticidad lo habían ido apartando progresivamente.

\section{Contexto y objetivos}

En ese año, el Patronato otorgó un nombre nuevo a la institución: Museo Nacional de Artes Decorativas. La justificación del acuerdo, que refleja un cambio de rumbo conceptual sustancial, aduce que la decisión se tomó para que el museo pudiera incluir

\footnotetext{
"obras de alto valor decorativo que, no siendo de producción industrial, son sin embargo las que en todas las épocas y países han mostrado los caracteres artísticos directrices en la producción de las artes industriales... En lo que no existen dudas es en que esas obras son siempre decorativas, pues el término 'industrial' es una modalidad del término amplio "decorativo"”.
}

Se opta, así, por una acepción restrictiva del término "industrial", que elimina los productos de la máquina que no estuvieran embellecidos por un valor añadido ornamental. De este modo se dio la espalda a las investigaciones de vanguardia que se abrían camino por esos años, como, por ejemplo, a la firma Rolaco, a Sert, a los muebles diseñados por los arquitectos de la Generación del 25...; al diseño contemporáneo, en suma. Ni siquiera el advenimiento de la República, que introdujo en el 
Patronato dos vocales designados por la Casa del Pueblo de Madrid, uno de los cuales fue el pintor Luis Quintanilla, cambió este estado de $\cos ^{8}{ }^{8}$.

Tras la Guerra Civil se ahondó la tendencia a buscar refugio en la decoración -con el ingrediente nacional triunfalista que cabe imaginar-, un criterio de acopio, y un pie forzado para la investigación, que no comprometían al museo en los debates contemporáneos. La producción coetánea quedó definitivamente olvidada, excepto en lo que se refiere a algunas especialidades como el belenismo o algunos tejidos. El pasado se convirtió en protagonista, y sobre todo el pasado nacional, el hogar español recreado a través de las distintas épocas y estilos. "El Museo orientará el afán artístico de nuestros artesanos y fomentará la investigación de nuestras artes decorativas", proclamaba, en 1941, la Revista Nacional de Educación, y proseguía:

"Tras el paréntesis de incuria artística, que trazó la dominación roja en Madrid, ha abierto de nuevo sus puertas, remozado y pujante, el Museo Nacional de Artes Decorativas, que en la maravillosa variedad de sus salas exhibe los valores artísticos de nuestra gloriosa artesanía, revalorizada hoy día por las sabias directrices del Movimiento Nacional"'.

\section{Las colecciones: organización y exposición}

En 1932, poco después del cambio de rumbo de 1927, el museo se mudó al palacete de la calle Montalbán en el que aún hoy está instalado ${ }^{10}$. Falta averiguar cómo fue entonces la exposición permanente ${ }^{11}$, que está mejor documentada a partir de 1941. Ya el anuario de 1916 expresaba el deseo de "una instalación más perfecta", que "debería llegar, en muchos casos, a formar habitaciones completas, y así los objetos expresarían perfectamente su fin de utilidad" ${ }^{12}$. Las fotos que se conservan de los inicios de los cuarenta muestran un museo que ha colmado esa aspiración, pero que ha sustituido la funcionalidad por una escenografía de pretensiones aristocráticas, que describe la revista citada: "Tres pisos, cuenta hoy el Museo. En la planta baja se exhiben los distintos tipos de objetos que decoraron nuestros palacios y casas: loza, vidrios, cueros y talla... En el piso principal se ha tendido a presentar habitaciones completas de un solo estilo... Suntuoso el salón dieciochesco...El dormitorio severo y adusto, del siglo XVII,... Luego, el comedor señorial" ${ }^{13}$, que evocaba los siglos XV y XVI.

8 M. CABAÑAS BRAVO, "La Dirección General De Bellas Artes republicana y su reiterada gestión por Ricardo de Orueta (1931-1936)", Archivo Español de Arte, LXXXII, 326 (2009), p. 175; J. GARCÍA FERNÁNDEZ, "La regulación y la gestión del Patrimonio Histórico-Artístico durante la Segunda República (1931-1939)", e-rph, 1 (2007), p. 14.

9 Revista Nacional de Educación, 2 (1941), pp. 87-90.

10 El traslado no fue inmediato: en 1933 todavía se anunciaba el museo en ABC en su antiguo domicilio de la calle Sacramento.

11 Sabemos que, al menos sobre el papel, la República creó un Museo del Encaje, dentro del Museo de Artes Decorativas con los fondos de la Fundación García Cabrero, y un Taller-Escuela del Encaje (Decreto de 16 de mayo de 1934). Enseguida pasó al Museo del Pueblo Español (Decreto de 26 de julio de 1934).

12 Anuario, op. cit., p. 10.

13 Revista Nacional de Educación, 2 (1941), p. 89. 
Pilar Fernández Vega, viuda del catedrático José Ferrandis, que también había trabajado en el museo, se hizo cargo de la dirección en 1941 y, bajo su férula, se acometió la ampliación del edificio, al que se agregaron dos plantas y un anexo. El proyecto de Luis Moya Blanco (1942-1944) se ejecutó solo en parte; no se materializó la parte escenográfica, uno de sus "sueños arquitectónicos", de la que se conservan solo dibujos. La reinauguración, en 1950, mostró una exposición permanente más grande, pero con una museografía muy semejante a la ya descrita: series tipológicas y ambientes.

Una nueva intervención, que fue abierta al público en 1972, al mismo tiempo que el Museo del Pueblo Español, cierra este período. El diario $A B C$ resaltaba esta coincidencia el día 12 de diciembre: "ambos recogen, de forma complementaria, aspectos tan destacados de la producción artística como son (sic) la creación popular y las artes decorativas" 14 . En la planta tercera se reservaron varias salas a las producciones "populares", que hoy más bien calificaríamos de regionales, diferenciadas por sus "estilos" locales. Quizá algo influyera en esta mirada el que ahora la Directora fuera María Dolores Enríquez, que había estudiado en el Instituto Escuela.

Y perduraba el contraste con las manufacturas de lujo, organizadas en ambientes historicistas. Manuel Pombo Angulo hace una lírica descripción del efecto logrado:

"Y el milagro se ha producido. Esta mañana, Doña Carmen Polo de Franco inauguró -sí, porque, en realidad, de una inauguración se trataba- el renacido, o, si se quiere, nacido, Museo de Artes Decorativas. Todo es en él ahora como si hubiese despertado de un sueño, en el que los fantasmas hubiesen cobrado vida, materializándose, como en el cuento de los cien años dormidos... un recreo constante para los que, de pronto, se encuentran con este museo, despierto ya de su maleficio, con música en los clavecines, y aire y no pátina en los abanicos"15.

En esta ocasión, además de consolidarse los cimientos, se ganaron una sala de exposiciones en la planta sótano, y un almacén planta quinta.

\section{Productos culturales y público destinatario}

Las necesidades que planteaba el museo tras la reinauguración de 1950, y que no logró satisfacer, suenan extrañamente parecidas a las actuales: "una publicidad acertada y establecer un horario de tarde". Esas son las razones a las que Lolita Enríquez atribuía el bajo número de visitantes ${ }^{16}, 3.484$ en 1966. El enfoque hogareño atrajo a un público fundamentalmente femenino, y el aspecto lujoso y recargado sedujo sobre todo a la burguesía acomodada.

De las actividades, destacan sobre todo las exposiciones de nacimientos, que se organizaron con periodicidad desde 1951. Han sido uno de los rasgos de identidad del museo hasta su reciente renovación conceptual.

$14 A B C, 12$ de diciembre de 1972, p. 122.

15 La Vanguardia Española, 30 de noviembre de 1972, p. 8.

16 Entrevista en $A B C, 24$ de enero de 1967, p. 63. 


\section{3-2003. Un nuevo sesgo profesional}

\section{Contexto y objetivos}

Poco a poco el museo se fue dotando de personal salido de las oposiciones de facultativos de museos. Los nuevos técnicos, junto con los directores Gabriel Moya Valgañón y Alberto Bartolomé Arraiza, introdujeron la estructura de tareas de la museología contemporánea, creando un museo de funciones, del que fue protagonista la documentación como criterio ordenador de la gestión de los fondos museográficos, como sucedió en muchos otros museos entre los años setenta y los noventa. De lo que en la profesión se conoce como "las fichas de Navascués", se pasó a la normalización documental promovida por la SGME, a cuyo desarrollo algunos de los miembros de la plantilla contribuyeron activamente.

Pero donde el museo se destacó como verdaderamente innovador fue en la implantación pionera de una política de conservación preventiva, que contribuyó a abrir paso en los museos estatales a la figura del conservador-restaurador. Cosa inusitada para aquellos tiempos, que ha creado escuela.

\section{Las colecciones: organización y exposición}

Algo se avanzó en estos años en la organización de la exposición permanente: en parte del conjunto de las salas se planteó un esbozo de separación física, y por tanto intelectual, entre las piezas y el público, al que se privó de la inmersión un tanto falsaria que suponía estar completamente rodeado de objetos, como si uno estuviera en su propia casa. Se formaron conjuntos de fondos museográficos agrupados por estilos, por funciones o por técnicas constructivas y decorativas. Además, en algunas zonas se recurrió a la exposición sistemática, ya existente antes en el museo, pero ahora puesta al día y concebida para expresar aspectos significativos de las formas de producción.

La gran novedad de este período fue la incorporación del diseño contemporáneo internacional a las colecciones históricas, gracias a la adquisición, en 1999, de la colección Bröhan, que dibuja una historia de la opción racionalista -aunque hay piezas de otras tendencias- del diseño industrial del s. XX, con alguna incursión en el diseño gráfico y en la indumentaria. Componen este fondo piezas de Frank Lloyd Wright, Alvar Aalto, Josef Hoffmann, Gerrit Rietveld, Mies van der Rohe - entre las que se encuentra un prototipo de la silla Barcelona-, Elsa Schiaparelli y Kandinski, entre muchos otros autores. 


\section{De 2003 hasta la actualidad}

\section{Objetivos y contexto}

Un plan museológico (2003) desarrollado en objetivos anuales (2003-2009), un plan bianual (2009-2010) y un plan director (2011), han sentado las bases de la renovación conceptual, cimentada en nuevos objetivos, presididos por la finalidad de contribuir a "diseñar nuestro entorno". El primero es transformar el museo "de los estilos" en el de la cultura material cotidiana, la de las artes y del diseño, enfocada desde un punto de vista contemporáneo, como instrumento de creación y formación, y como motor económico; pero con el matiz de poner de relieve todo aquello que ha contribuido a crear, ayer y hoy, un entorno vital de calidad, socialmente responsable. Además, el MNAD se ha comprometido con la reinterpretación de sus colecciones, contextualizadas de manera que muestren los valores de producción y de comercialización, creativos, de uso, ideológicos y simbólicos de los objetos.

Para ello, el museo desarrolla un conjunto de programas generales, entre los cuales destacan los siguientes:

El programa de exposiciones temporales da prioridad a las dedicadas al diseño contemporáneo y a las relecturas de la colección. Estas últimas, denominadas "experimentales", siguen la metodología de lo que Ángela García Blanco ha denominado más de una vez "exposición comunicativa", que incorpora al público como co-creador, merced a la realización de estudios que comprenden las evaluaciones previa, formativa y sumativa; a través de ellas, los visitantes reales y potenciales contribuyen a conformar los objetivos del proyecto y el proyecto mismo, y a dar legibilidad al discurso, a la información y a la museografía. Así se abordó la exposición "Fascinados por Oriente". Y en "Diseño contra la pobreza" se ha dado otro paso: fue fruto de la colaboración, en pie de igualdad, de diversos agentes, entre los que se contaban el sector del diseño profesional, las ONGs dedicadas a la atención de personas sin hogar y un grupo de estas. Con estas contribuciones, el MNAD pretende acercarse a los modelos de "museo foro" y "museo-media"

Una metodología similar se está aplicando para la renovación de la colección permanente, abordada por un grupo de trabajo ad hoc. Por el momento se ha realizado una evaluación preliminar con el público real y potencial de la institución, y se pretende recurrir a la contribución de sectores profesionales de interés - del diseño, de la comunicación, de la pedagogía, de la empresa-y a estudiantes del área conceptual que abarca el museo, a través de un panel delphi, de focus groups y de escenarios de futuro.

El compromiso con la formación ha dado lugar al programa "Diseño y pedagogía", que ofrece el museo como material de trabajo para que adolescentes y jóvenes elaboren respuestas a problemas concretos de creación y producción ${ }^{18}$, en el marco de pro-

17 L. CABALLERO GARCÍA y R. CASTILLO GARCÍA, "Diseño contra la pobreza: la sociedad civil como emisor", Museos.es, 7-8 (2011-2012), p. 408.

18 Con la Escuela de Arte 10 de la Comunidad de Madrid, de diseño gráfico, se abordó "Fantasy Design" en el marco de un proyecto europeo; con la Escuela 12, de diseño industrial, el proyecto Memoria 1+2, cuya 
yectos de curso de Bachillerato, de Formación Profesional o de educación universitaria. Todos ellos han sido objeto, a su finalización, de exposiciones temporales.

A partir de estas experiencias, se ha ido configurando una línea de actuación de marcado compromiso con los sectores de la población excluidos por diversas causas. Un hito importante han sido los talleres y la subsiguiente exposición "Enganchados al arte. Mi techo, mi espacio íntimo, mi hogar...", un proyecto de Cruz Roja, de valor terapéutico para drogodependientes. Seguirán otros del mismo tenor.

Los productos culturales del MNAD evolucionan progresivamente desde la transmisión de saberes al fomento de acciones creativas que permitan a todos los tipos de público construir sus propios conocimientos. Se trata, finalmente, de dar a luz un museo comunicativo. A ello ha contribuido no poco la adopción de la dinámica colaborativa, es decir, del sistema de trabajo modular o por proyectos, que coexiste con el funcional: los departamentos cumplen con las tareas ordinarias, pero las de mayor envergadura, sobre las que pivota la identidad del museo, son desarrolladas por equipos interdisciplinares, en los que a menudo participan especialistas externos y otras instituciones.

A estos programas se añaden otros: el museo en la web, el centenario del MNAI/ MNAD, la accesibilidad y mejora del servicio, el incremento de la participación ciudadana, o la mejora de la distribución espacial, las infraestructuras y el equipamiento, además de los propios de los distintos departamentos.

\section{Conclusión}

Todos los museos - a través tanto de sus exposiciones, permanente y temporales, como de sus productos culturales-, han interpretado sus colecciones desde la ideología y los valores coetáneos. El MNAI se enroló, aunque un poco tardíamente, en el fomento de los productos de la segunda Revolución Industrial, enfrentada a la contradicción entre la pervivencia de unos estilos históricos de éxito probado, y la inevitable emergencia de la estética de la máquina. El MNAD acabó por perder la batalla de la modernidad, sobre todo cuando, tras la Guerra Civil, el franquismo lo utilizó para consagrar una imagen triunfal de lo español. Hoy pretendemos poner el museo al servicio de los intereses y expectativas de un público inmerso en una crisis socioeconómica en la que la sostenibilidad, la interculturalidad y la solidaridad son los valores sobre los que se podría construir un futuro mejor. En ello, y en saber un poco más sobre nosotros mismos y nuestro pasado, está empeñado el MNAD.

Para finalizar, volvamos a la cuestión de la denominación. Los trabajadores del museo tenemos algunas ideas, pero será el futuro el que nos revele cuál será nuestro nombre. El Ministerio de Educación, Cultura y Deporte y los expertos, diseñadores, artesanos, estudiantes y el resto de nuestros aliados tendrán mucho que decir al respecto.

tercera convocatoria está en curso al redactar estas líneas; con el Istituto Europeo di Design, el proyecto de renovación de la identidad corporativa del museo y los trabajos del Máster de diseño textil de superficies; con la Universidad Europea de Madrid, el diseño de la página web, también en curso. 